\title{
Aydın Söke'de Bulunan Manol Evi Hamamında Tesisat ve Isıtma Sistemi
}

\author{
The Water and the Heating System in the Bath of Manol Household in Söke, Aydın
}

\author{
Elif Gürsoy* ${ }^{*}$
}

Öz

Antik dönemden itibaren yıkanmaya ve hamam inşasına büyük önem verildiği bilinmektedir. Yıkanma faaliyeti gerek çarşı hamamları gerekse özel hamamlarda gerçekleştirilirken yaşanılan konutlarda da çeşitli birimler oluşturulmuştur. Konutta ev hamamı kullanımının yanında odalarda özel olarak tasarlanmış çeşitli yıkanma hacimlerinin de yer aldığı bilinmektedir.

Bu çalışmaya konu olan yıkanma mekânı Aydın ili Söke ilçesinde yer alan Manol Evi’nde bulunmakta olup 2020 yılı içerisinde sürdürülmekte olan restorasyon çalışmaları sırasında ortaya çıkarılmıştır. Çalışma dâhilinde Manol Evi hamamı, görsel verilerle tanıtılmış ve ev hamamlarında tesisat ve ısıtma sistemi hakkında bilgiler sunulmuştur. Konut içerisindeki yıkanma mekânı olan hamam odası, mutfak mekânı ile bitişik konumdadır. Hamamın mutfak ile olan bağlantısı Antik dönem örneklerinden itibaren karşılaşılan bir uygulamayı işaret etmekle birlikte tesisat ve ısıtma sistemi hakkında detaylı bilgilere de ulaşılmasını sağlamıştır. Manol Evi hamamında, tesisata ait kazan ve musluk kullanımına dair izler yer almakla birlikte, ısıtma sistemine yönelik ateş haznesi, cehennemlik ve baca bölümleri ortaya çıkartılmıştır.

\section{Anahtar Kelimeler}

Hamam, Yıkanma, Banyo Kültürü, Ev Hamamı, Isıtma Sistemi

\begin{abstract}
Besides the importance attached to bathing and building baths since the Ancient Period. While the bathing activity was being carried out in both the bazaar baths and private baths, various units within the household were being created. Besides the use of household baths in the residence, it is also known that some custom-designed various of bathing spaces were also existing in the rooms. These sections exhibit two different uses, with their functions as both a closet for placing the belongings and a spot for having a bath. It does not additionally include its water and heating system and it is only designed with a simple assembly that provides the flow of the water that is used for bathing.

The bathing place that constitutes the subject of this study, is located in the Manol House which is located in the Söke District of Aydın, and it was encountered in the restoration works carried out in 2020. Within the study, the Manol House bath is introduced with visual data, and information about the water and heating system in household baths is presented. While the connection of the bath with the kitchen points to an application that we start to witness together with the examples of the ancient period, detailed information about water and heating system can also be reached. While there are traces of the usage of boiler and tap in the water system, we come across a fire chamber, a hotspot, and a chimney in the heating system.
\end{abstract}

\section{Keywords}

Bath, Bathing, Bath Culture, Household Bath, Heating System

* Sorumlu Yazar: Elif Gürsoy (Doç. Dr.), Uşak Üniversitesi, Fen Edebiyat Fakültesi, Sanat Tarihi Bölümü, Uşak, Türkiye. E-posta: elif.gursoy@usak.edu.tr ORCID: 0000-0003-0147-8682

Atıf: Gursoy, Elif. "Aydın Söke'de Bulunan Manol Evi Hamamında Tesisat ve Isıtma Sistemi." Art-Sanat, 17(2022): 157-176. https://doi.org/10.26650/artsanat.2022.17.930651 


\section{Extended Summary}

Washing, which signifies spiritual and symbolic purification, is also very important in Islam in addition to material and physical cleaning. The hammam stands out with this significance as construction where the cleaning and washing take place. A high number of hammams were constructed in Anatolia with the Seljuks' settlement. While some small private hammams were constructed aside from the hammams in bazaars which provided income for foundations, there were also some small and privately owned hammams in mansions and waterfront houses in the big cities and ayan mansions in Anatolia, which were separate from the main building. Bathing cubicles or bathroom cabinets were planned within the house for a similar purpose. With the allocation of each room to one family in the house, the ablution ritual was meant to be performed within the privacy of the room. For this reason, the lower part of the closet, which we encounter in every room and sometimes even in the kitchen, was arranged suitably for washing.

A bath chamber adjacent to the kitchen space was encountered in the restoration works carried out in 2020 in the Manol House which is located in the Söke District of Aydın. While the connection of the bath with the kitchen points to an application that we start to witness together with the examples of the ancient period, detailed information about water and heating system can also be reached. While there are traces of the usage of boiler and tap in the water system, we come across a fire chamber, a hotspot, and a chimney in the heating system.

Located in Aydın Province, Söke District, Kemalpaşa Neighborhood, Island 333, Plot 11, Manol House consists of two floors on the ground floor. Along with an outbuilding planned independently of the building, the garden entrance and the main entrance of the house are located on Alay Street. The house and the outbuilding adjacent to it in the south are covered with Turkish-style tiles.

Manol House consists of two floors above the basement. The main building and the annexe are covered with Turkish-style roof tile. There are two units in the basement of the housing. The ground floor and first floor are in a different types of floor plans. While the side anteroom and three rooms connected to the side anteroom are placed on the lower floor, the middle anteroom and five rooms are viewed on the upper floor. There is an annexe that is joined to the house in the southwest of the house. The annexe with two-unit which is composed of a kitchen and a Turkish bathroom room that is next to the kitchen is one storey.

The restoration work has been started at Manol House by Söke Municipality in 2010 and the House has been planned to be converted into a Guest House. During the restoration works, the Turkish bathroom room which presents ideas regarding the installation and heating system, and consists of a single unit, has been encountered. 
The house has a garden in the southern part and an outbuilding located in the southwest. The passage between the house and the outbuilding is enabled by a hallway on the ground floor of the house. The cement tile floor covering continues in the passage area as in the house's corridor.

When the hammam examples in the house or the outbuilding section, for which there is limited information in the sources, are examined, the connection between the hammam and the kitchen space shows similar characteristics. The hammam section was evaluated together with such units as the kitchen and cellar on the ground floor. The hammam was also considered together with the resting or the preparation unit in front of it, and the arrangements consisting of two spaces similar to the examples from the $20^{\text {th }}$-century Aydin and the $19^{\text {th }}$-century Tokat attracted attention. Although it was thought that the unit providing access to the hammam in the Manol House was organized together with it, there was no definite information.

Despite the insufficient information about the heating system in the hammams of private houses, an evaluation was possible with the removal of the floor in the example of Manol House. In the hammam, the reflection of the hypocaust section of the Roman and Turkish hammam architecture on a small area was observed. Similar arrangements, in which the furnace section and the heating principle of the water in the tank of Turkish hammam were repeated with a basic model, were also available in hammam spaces in Aydın, Erzurum and Çorum.

Although the fire chamber and boiler, the faucet that enables the hot water flow, the chimney, and the carriers of the heating system were found in the Manol House example, there was no trace of such sections as berm, basin, or lampstand which are normally expected to be in the hammam space. It was considered probable that these marks disappeared in later interventions. However, when the limited examples in Anatolia were examined, it was thought that the bench and lamp elements were to be found on the facade connected with the kitchen where the cauldron was located.

Local examples and general characteristics can be ascertained if more hammam examples designed for private use in Söke District and other regions are accessed. However, the potential for these places being changed is extremely high in these currently inhabited historical buildings due to their continuous use and various additional requirements and technologies. Later requirements can lead to the end of old practices, and in some cases, it becomes necessary in terms of ensuring the continuity of life. This problem is particularly noticeable in hammams and other bathing places which include such important technologies as plumbing and heating systems. Although there are possibly many cases that could not resist the developing and convenient technologies and disappeared or underwent changes, the restoration activities to be conducted over time show their importance with the discovery of various information as in the example of Manol House. 


\section{Giriş}

Geleneksel Türk Evi, kendine has özellikleri içinde barındırarak Anadolu'da kendi kimliğini oluşturmuş, sonrasında Osmanlı toprakları sınırları dâhilinde, Balkanlar'da ve Avrupa'nın diğer bölgelerinde gelişimini sürdürmüştür. 15. yüzyıldan itibaren diğer ev tiplerinin yerini almaya başlayan Türk evi, en fazla 17. ve 18. yüzyılda yayılım göstermiştir ${ }^{1}$.

Plan şemasına bakıldığında sofasız, dış sofalı, iç sofalı ve orta sofalı plan uygulanmakta olup odalar sofanın uzantısıyla ayrı mekânlar hâline gelmekte, aynı zamanda birbirlerine bağlanmaktadır². Genel olarak tek katlı veya iki katlı tasarlanan Türk evinde, iki katlı örneklerde alt kat çoğunlukla servis mekânları olarak kullanılmakta ve üretime dair ambar, samanlık ve ahır gibi bölümleri içermektedir. Üst kat ise yaşama alanlarını kapsamaktadır . Türk evinde en sık rastlanan yapım tekniği, ahşap çatkı arası dolgu veya bağdadi olmakla birlikte temel yapı malzemeleri ahşap, taş ve tuğladır. Bunun yanında bozkırın hâkim olduğu bölgelerde yapı malzemesi olarak sıklıkla kerpiç kullanılmaktadır'.

Türk konut mimarisi içerisinde, Aydın ili örnekleri incelendiğinde, plan şemalarına göre, yan sofall, dış sofall, T sofal, orta sofalı ve merkezi sofalı evler görülmektedir. Konutlar genellikle yaşam birimi ile bu birimin arkasında yer alan avlulardan oluşmaktadır. Aydın evlerinde genellikle evler, yola bakan yaşam birimi, bu birime bitişik sslak hacim birimleri ve avludan meydana gelmektedir. Genellikle evlerin zemin kat1, avluya ve avluda bulunan banyo, mutfak, tuvalet gibi sslak hacimlerden oluşan ek birime bağlanmaktadır. Bu bağlantı bazen bir koridorla ya da bir mekânla sağlanmaktadır. Ek mekânlar, yapı ile bitişik veya yapı içerisinden geçilecek düzende avluya yapılmaktadır, bunun dışında bazı örneklerde ıslak hacimler yapı içerisinde bulunmaktadır ${ }^{5}$.

Aydın geleneksel konut mimarisi konusunda, Türk Evi (Açık dış sofalı plan tipi / Kapalı dış sofalı plan tipi), Rum Evi (Yan hollü plan tipi / Orta hollü plan tipi / T formunda hollü plan tipi) ve Etkileşim Yapıları (Yan hollü plan tipi / Orta hollü plan tipi / T formda hollü plan tipi / L formda hollü plan tipi) olarak çeşitli gruplar çalışmalarda yer bulmuştur. Aydın ili özelinde yapılan bu tipolojik yaklaşımda sofa, planın belirleyicisidir. Bu plan şemalarından Etkileşim Yapıları, en fazla görülen yapı tipini

1 Sedad Hakkı Eldem, Türk Evi Plan Tipleri (İstanbul: İstanbul Teknik Üniversitesi Mimarlık Fakültesi Yayını, 1995).

2 Reha Günay, Türk Evi Geleneği ve Safranbolu Evleri (İstanbul: YEM Yayınları, 1998); Sedad Hakkı Eldem, Türk Evi Plan Tipleri (İstanbul: İstanbul Teknik Üniversitesi Mimarlık Fakültesi Yayını, 1995).

3 Cengiz Baktaş, Türk Evi (İstanbul: Yapı Kredi Yayınları, 1996).

4 Haluk Sezgin, "Yöresel Konut Mimarisi ve Türkiye'deki Örnekleri Hakkında," Tasarım Kuram Dergisi 3/4 (2006), 1-20; Gökhan Uşma ve Nur Urfalığlu, "Geleneksel Van Evlerinin Cephe Özellikleri ve Tipolojisi Üzerine Bir İnceleme,” Çukurova Üniversitesi Mühendislik Mimarlık Fakültesi Dergisi 33/1 (2018), 4.

5 Gökçe Şimşek, “Aydın'da Mimarlık Mirası Olarak Cumhuriyet Dönemi Konutları,” Megaron 10/1 (2015), 51-52. 
oluşturmaktadır. Etkileşim yapılarının 1925 yılından sonra yaygınlaşmaya başladığı düşünülmekle birlikte, ilk olarak Rum ve Macar yapı ustaları tarafından Türkler için yapıldığı fikri öne çıkmaktadır. Daha sonraki dönemlerde, Türk yapı ustalarının da aynı tarzda yapılar inşa ettiği görülmüştür ${ }^{6}$.

Aydın ilindeki yan sofalı konutlarda, sofa daha geniş tutulmuştur. Bu plan tipindeki yapılarda asimetrik cephe düzeni görülmekle birlikte az sayıda örneği mevcuttur. D1ş sofalı konutlarda, yaşama biriminde sofa, avlu cephesine paraleldir. Sofanın her iki yanında birer oda yer almakla birlikte bu odalar yapının sokak cephesini oluşturmaktadır. Dış sofalı plan tipi, Aydın konutlarında daha sık uygulanmıştır. T şeklinde bir sofa ile sofanın her iki yanında birer odanın kullanıldı̆̆ cephesine, diğer kolu ise avluya paralel uzanan sofanın bir köşesine yerleştirilmiştir. Dış sofalı örnekler gibi T sofalı konutlar da sayıca fazladır. Orta sofalı konutlarda sofa, yaşam birimini avluya dik olarak bölmüş ve ortada konumlanmıştır. Orta sofanın her iki yanında genellikle ikişer oda bulunmaktadır. Merkezi sofalı plan şeması uygulaması nadir olup kaynaklarda yalnızca bir örnekten bahsedilmiştir ${ }^{7}$.

Aydın ilindeki tarihî konutlarda genellikle temeller, bodrum kat ve birinci katta taş ve tuğlanın birlikte kullanıldığı kâgir örgü sistemi görülmüştür. Birinci katın avluya bakan cephesi, ahşap karkas sistemle inşa edilmiş; kimi örneklerde zemin ve birinci katlarda harman tuğlası ile örülmüş duvarlar yer almıştır. Kat döşemesi ve merdivenlerde ahşap malzeme, çatıda Marsilya tipi kiremit kullanılmıştır ${ }^{8}$.

Farklı coğrafyalarda, planlamasında görülen çeşitlilik ile şekillenen Türk evinde yıkanma kültürü, bu kültürü somut olarak yansıtan yıkanma biriminin doğmasına sebep olmuştur. Çalışma kapsamında, Manol Evi özelinde yıkanma birimi düzenlemesi, tesisat ve 1sıtma sistemi uygulamaları konu edilmiştir.

\section{Türk Evi’nde Yıkanma}

Y1kanma, maddi ve bedenî bir temizlik olmasının yanında manevi ve sembolik arınma anlamı taşımaktadır. İslam dininde benzer şekilde manevi temizlik ve çevre temizliği önemli görülmektedir’. Temizlik ve yıkanma işleminin gerçekleştiği yap1 durumdaki "hamam", Arapçada "1sıtmak, sıcak olmak" anlamındaki hamm kökünden türetilmiş ve "1sıtılan yer, yıkanma yeri” anlamında kullanılmaktadır".

6 Aylin Ertem, “Aydın Kent Merkezinin Tarihi Dokusunun İncelenmesi” (Yüksek Lisans tezi, Dokuz Eylül Üniversitesi, 2000), 86.

7 Gökçe Şimşek, “Aydın’da Mimarlık Mirası Olarak Cumhuriyet Dönemi Konutları,” 52-56.

8 Gökçe Şimşek, “Aydın’da Mimarlık Mirası Olarak Cumhuriyet Dönemi Konutları,” 54.

9 Mehmet Kâmil Yaşaroğlu, "Hamam III. Fıkıh,” TDV İslam Ansiklopedisi, c. 15 (İstanbul: Türkiye Diyanet Vakfi Yayınları, 1997, 433.

10 Semavi Eyice, “İznik'de Büyük Hamam ve Osmanlı Hamamları Hakkında Bir Deneme," İstanbul Üniversitesi Edebiyat Fakültesi Tarih Dergisi 11/15 (1960), 99-120; Semavi Eyice, "Hamam I. Tarih ve Mimari," TDV İslam Ansiklopedisi, c. 15 (İstanbul: Türkiye Diyanet Vakfı Yayınları, 1997), 402. 
Tarihte, Roma hamamları, Türk hamamlarıla büyük benzerlik göstermektedir. Antik dönemde Orta İtalya köylerindeki halkın tıp alanındaki geleneklerine bağlı olarak, mutfakta soba ya da ocak önünde terlemenin mevsimlik rahatsılıkların tedavisinde veya romatizmal ağrıların giderilmesinde önemi bilinmekteydi. Campania ve Latium'daki çiftlik evleri ile villalarda genellikle bu amaç için özel bir odanın kullanıldığg belirtilmektedir. Bu uygulamanın daha geniş biçimi, daire planlı küçük bir oda olan ve üzeri kubbe ile örtülü sıcaklık biriminden oluşmaktadır. Banyo yapmakta olan kişiyi soğuktan koruma amaciyla orta derecede 1sitılan bir diğer odayla bağlantılı konumlandırılmış bu düzenlemede, ikinci oda geçit görevi görmesinin yanında, giyinme ve soyunma için de kullanılmaktadır. Özel yıkanma dairesi olarak tasarlanmış bu mekânlar, işlevsel nedenleri ile mutfağın hemen bitişiğinde yer almaktadır. Böylece, 1sıtmada da ortak kullanım mümkün hâle gelmektedir ${ }^{11}$.

Antik dönemde ev hamamlarının en erken örnekleri MÖ 2. yüzyıl başlarına tarihlenirken, daha geç döneme ait olanların daha gelişmiş bir 1sıtma teknolojisine sahip olduğu anlaşılmaktadır. Erken Roma döneminde özel konutlarda bulunan hamamlar 3 gruba ayrılmıştır: Bunlardan Tip 1 ve Tip 2 mutfağın hemen yanında yer almış ve ısıtma donanımını mutfakla paylaşmışır. Tip 3 örnekleri, bağımsız kuruluşlardır ve kendi sistemleri ile 1sıtılmıştır. Bu son tip, aynı zamanda İmparatorluk döneminin daha büyük özel villalarındaki hamam dairelerinin de öncüsü kabul edilmiştir ${ }^{12}$.

Anadolu konut mimarisi örnekleri incelendiğinde Antik dönem uygulamalarına benzer şekilde, şehirlerdeki konak ve yalılarda, büyük şehirler dışında âyan konaklarında ana binadan ayrı küçük boyutlu özel hamamların inşa edildiği görülmektedir. Saray, konak ve yalı hamamları tek bir yapı içine toplanmış ve birkaç metrekarelik küçük hacimlerden oluşmuştur. 18. ve 19. yüzyllda genellikle tuğla malzemeden inşa edilen bu hamamların tek mekândan ibaret olanları dışında, camekân, 1lıklık, sıcaklık ve külhan bölümlerinden meydana gelenleri de tespit edilmiştir. Örneklerin bazılarında filgözü pencere açılıkları dışında 1şıklandırma için nişler ya da lambalıklar bulunmaktadir ${ }^{13}$.

Anadolu örneklerinde avluda ya da ana yapının zemin katında yer alan, ailenin yıkanma gereksinimini karşılayan hamam mekânının teknik kolaylık açısından, Erken Roma dönemi ev hamamlarında olduğu gibi mutfakla bağlantısı görülmektedir ${ }^{14}$. Ayrıca mutfak ve hamam evin içinde konumlandırılmak istenir ise, sofanın bir ucuna

11 Yılmaz Önge, “Anadolu'da Türk Hamamları Hakkında Genel Bilgiler ve Mimar Sinan'ın İnşa Ettiği Hamamlar," Mimarbaşs Koca Sinan Yaşadığı Çă̆ ve Eserleri 1 (İstanbul: Vakıflar Genel Müdürlügü̈ Yayınları, 1988), 403; Fikret Yegül, Antik Çă̆'da Hamamlar ve Yıkanma (İstanbul: Homer Kitabevi, 2006), 47-48.

12 Yegül, Antik Çă̆'da Hamamlar, 19.

13 Ömer İskender Tuluk, "Erken 20. Yüzyıl Çorum Evlerinde Banyo Teknolojisi," ODTÜ Mimarlkk Fakültesi Dergisi 27/2 (2010), 61-63.

14 Yüksel Göğebakan, "Karakteristik Bir Değer Olan Geleneksel Türk Evi’nin Oluşumunu Belirleyen Unsurlar ve Bu Evlerin Genel Özellikleri,” İönü Üniversitesi Kültür ve Sanat Dergisi 1/1 (2015), 52. 
yerleştirilmektedir ${ }^{15}$. Bazı yapılarda, hamam odası bulunsa da oda içerisinde ayrıca gusülhanelere yer verilmiştir ${ }^{16}$.

Selçukluların Anadolu topraklarına yerleşmesiyle yoğun bir hamam inşası söz konusu olmuştur. Vakıflara gelir sağlamak amacıyla yapılan çarşı hamamları dışında konaklarda esas binadan ayrı, küçük çapta özel hamamlar da tasarlanmıştır ${ }^{17}$. Bunun yanında konut dâhilinde gusülhaneler ya da banyo dolapları planlanmıştır. Ev hamamlarına kıyasla genellikle, konut dâhilindeki gusülhaneler çalışmalara daha fazla konu edilmiş, böylece yıkanma adabı ve tesisata yönelik fikirlere de daha çok gusülhaneler özelinde ulaşılabilmiştir. Anadolu'nun çeşitli bölgelerinde gusülhane, çol, çark, çarh, yunmalık, kirelik, hamam, hammamcık, hamamlık, hammamcuk ya da küçük hamam gibi farklı isimlerle ve düzenlemelerle yıkanma birimlerinin tasarlandığ 1 görülmüştür ${ }^{18}$.

Konutta her odanın bir aileye ayrılmasıyla, gusül abdesti alma eylemi odanın gizliliği içerisinde çözülmeye çalışılmış ve bu nedenle her odada, bazen mutfakta bile karşımıza çıkan yüklüğün alt bölümü, gusülhane olarak kullanılmıştır. Yüklüğün kapakları açıldıktan, yataklar yere indirildikten sonra, yüklük tabanı olan kapak kaldırılınca yıkanılan mekân ortaya çıkmıştır ${ }^{19}$. Gusülhanelerde akan sudan ziyade ibrik, kazan gibi geleneksel malzemelerle su, bu bölüme taşınmıştır ${ }^{20}$. Temizlik işlemi, alçak taburelere oturularak, ocakta gügümlerde ya da tenekelerde isitılan su ile yerine getirilmiştir. Bu mekânın zemini hafifçe dışarıya doğru meyillidir ve kirli su, borularla dışarı akıtılmıştır ${ }^{21}$. Odalarda genellikle ocağın yanında bulunan gusülhaneler, 1sı kaybının önlenmesi açısından genellikle ocağın yan bitişiğinde veya yan odadaki ocakla sırt sırta gelecek şekilde tasarlanmıştır ${ }^{22}$. Gusülhaneler, köklü bir insan temizliğine hizmet etmekten ziyade, su dökünmek ya da boy abdesti almak için düşünülmüştür ${ }^{23}$.

Konutlarda, ocaklı odaların hemen hepsinde gusülhaneye rastlanılmaktadır. Gömme dolaplardan büyük olanı çoğu kez gusülhane şeklinde değerlendirilmekte ve ka-

15 Nigan Bayazıt, "Safranbolu Evlerinin Plan Tipolojisi ve Kullanıcı İhtiyaçları Hiyerarşisi," Tasarım-Kuram 17 (2014), 3.

16 Tuluk, "Erken 20. Yüzyıl Çorum Evlerinde Banyo Teknolojisi," 64.

17 Eyice, "Hamam I. Tarih ve Mimari," 402-414.

18 Raziye Çiğdem Önal, "Erzurum/İspir İlçesinde Geleneksel Ev Mimarisi,” XX. Uluslararası Ortaçağ Türk Dönemi Kazıları ve Sanat Tarihi Araştırmaları Sempozyumu, 02-05 Kasım 2016 Bildiriler, 2 (Sakarya: Sakarya Üniversitesi Yayınları, 2016), 752; Emrah Bozok, "Türkçenin Söz Varlığında Temizlik Kavramı Alanı," (Doktora tezi, Ondokuz Mayıs Üniversitesi, 2018), 219.

19 Mehmet Erman Arslan, "Türkiye'deki Geleneksel Konut Tipolojisi ve Bileşenlerinin Sürekliliği,” (Yüksek Lisans tezi, Beykent Üniversitesi, 2012), 45.

20 Tuluk, "Erken 20. Yüzyıl Çorum Evlerinde Banyo Teknolojisi," 63.

21 Mahmut Davulcu, “Ormana Yöresi Geleneksel Konut Mimarisi ve Yapıcılık Geleneği,” Kalemişi 3/5 (2015), 67.

22 Özgenaz Dağ, “Geleneksel Amasra Evleri Plan Tipolojisi,” (Yüksek Lisans tezi, İstanbul Aydın Üniversitesi, 2017), 35 .

23 Sabit Oymanel, Hatice Kıran Çakır ve Özlem Sallı Bideci, "Geleneksel Mimari Uygulamaların Yorumlanmas1," 6th International Advanced Technologies Symposium, 16-18 May 2011 (Elazı̆̆: Elazı̆̆ Üniversitesi Yayınlar1, 2011), 79. 
pakları, dolap ve yüklüklerinki ile aynı özellikte imal edilmektedir. Bazı örneklerde, ortadaki ocağın bir tarafındaki gusülhane ile ocağın diğer tarafındaki dolap, oda içerisinde simetrik düzeni de sağlamaktadır ${ }^{24}$.

Manisa çevresindeki köy evleri, her odada birer gusülhane yer alacak şekilde düşünülmüştür. Yunddağ çevresi köylerinde bu bölüm, genellikle dolaptan ayrı, 80x80 cm ölçülerinde, ahşaptan yapılmış küçük bir mekân hâlindedir. Demirci, Selendi ve Kula çevresinde sineklik adıyla da bilinen gusülhane geleneği İzmir, Denizli ve Aydın çevresi köylerinde de görülmektedir. Kayseri, Niğde çevresinde bu bölüme musandıra adı verilmiştir ${ }^{25}$.

Erzurum'da geleneksel İspir evlerinde temizlik için kehrizler ve gusülhaneler olmak üzere iki ayrı yapı elemanı kullanılmıştır. Anadolu'nun farklı yörelerinde, mil, suluk, çaytaşı gibi adlarla bilinen kehrizler, ahşap bir kapakla üzeri kapatılıp açılabilen, beden duvarlarından dışarıya ya da plastik borularla duvar içinde giderleri bulunan, 80x80 cm ile 120x120 cm arasında boyutları değişen yıkanma alanlarıdır. Zeminleri ahşap ya da beton malzemedendir. Tabanında suyun akışını sağlamak amacıyla oluklar vardır. Erzurum'da yıkanma alanlarını tarif eden kehrizler dışında gusülhaneler de kullanılmıştır. Erzurum evlerindeki gusülhanelerde, ocaklarda isıtılan su, kazanlar vasıtasıyla soğuk su ile 1lıştırılarak kullanılmıştır. Örneklerin bir kısmında su 1sıtma sistemi, duvar içerisinde yer alan bakır kazanın alttan ateşle 1sıtılmasını sağlayan bir düzeneğe sahiptir. Bakır kazandaki suyu ısıtan haznenin girişi, gusülhane içinde ya da bitişiğindeki odanın ocaklığında bulunmaktadır ${ }^{26}$.

Erzurum'da geleneksel İspir evlerinde görülen bakır kazanın alttan 1sıtma sistemine benzer şekilde, 20. yüzyılda Çorum'da yer alan konak ve evlerin bazı gusülhanelerinde de suyu isıtma ve kullanmaya yönelik uygulamalar açısından Hanoğulları Konağ1 örneği fikir vermektedir. Konakta duvar içerisinde bulunan bakır kazanın 1sıtılmas1na imkân veren bir düzenek söz konusudur. Bakır kazan, kemerli bir niş içerisinde duvara gömülerek yanındaki kemerli nişin tabanından kazanın altına doğru açılmış haznedeki ateş ile 1sıtılmaktadır. Ateşten çıkan dumanın ocaklığın bacası ile tahliyesi sağlanmaktadır. Kazandaki suyun tahliyesi, kazanın tabanına yakın bir bölümde yer alan musluk ile yapılmaktadır. Isıtılan su, musluk elemanının altında, içerisinde soğuk suyun bulunduğu başka bir kazana aktarılarak yıkanmaya hazır hale getirilmektedir ${ }^{27}$.

Çol, çark ya da çarh, Harput, Elazı $\breve{g}$, Bitlis ve Van'da genellikle evlerin zemin kat, tandır evi ve nadiren de olsa evlerin üst katlarının sofalarında yer almıştır. Kare veya dikdörtgen planlanan bu birimler çoğunlukla yekpare taştan imal edilmiştir. Zemine

24 Yüksel Sayan, Uşak Evleri (Ankara: Kültür Bakanlığı Yayınları, 1987), 117.

25 Bekir Deniz, “Manisa Yöresi Köy Mimarisi,” Arkeoloji-Sanat Tarihi Dergisi 5 (1992), 39.

26 Önal, "Erzurum/İspir İlçesinde Geleneksel Ev Mimarisi," 752.

27 Tuluk, "Erken 20. Yüzyıl Çorum Evlerinde Banyo Teknolojisi,” 64-75. 
gömülü basit yıkanma birimleri olan çol, bulaşık yıkama, çocukların yıkandığı ve abdest alma yeri gibi işlevlerle; gusülhanelerin bulunmadığı evlerde duş alma yeri olarak kullanılmıştır. Kapaklı olanlar, geleneksel Türk evlerindeki gusülhanelerle aynı özellikleri taşımaktadırlar ${ }^{28}$.

Ev, konak, köşk, saray gibi yapıların bir bölümünü oluşturan ve genellikle bir ya da birkaç mekândan ibaret özel hamamlar, yıkanma işleminin konut dâhilinde gerçekleşmesini sağlamaktadır. Bitlis’te tarihî evlerin bir kısmında, özellikle varlıklı ailelere ait evlerde altı köşeli, yedi köşeli, kare, dikdörtgen ya da silindirik planlı hamamlar görülmektedir. İçten kubbe veya tonoz örtülü mekânları, ocak ve kurnası bulunan hamamlar gusülhanelere göre çok daha kapsamlıdır. Genellikle evlerin planlarında dışa yarım ya da çeyrek daire şeklinde dışa taşıntılı inşa edilen hamam, tek hacimli mekânlardan ibarettir. Bitlis'te Müftüler Evi, İsa Kalkan Evi (1897), Yusuf Paşa Konağı (1899), Abdülmecid Eren Evi (1910), Burhan Bayhan Evi (1860) hamamları, ev hamamlarına örnek olarak gösterilebilir. Bitlis örneklerinden farklı olarak soğukluk kısımlarına sahip Diyarbakır'daki ve Urfa' daki konut hamamlarındaki birimler kubbelidir. Kayseri, Kütahya, İzmit, Edirne ve Manisa konutlarında da ev hamamlar1nın örnekleri görülmektedir. Bunlardan Manisa Zeytinliova'daki Kara Osmanoğlu Konağı'nda, avlunun güneyine yerleştirilen hamam, sıcaklık, soyunmalık ve giriş bölümünden oluşmaktadır ${ }^{29}$.

İç avlu etrafında gelişen bir ve iki katlı tasarlanan Urfa evlerinde, zemin kat, günlük oturma ve servis mekânlarını içermekteyken; mutfak/tandırlık, ahır/develik, hamam, hela ve yiyecek dolapları ise zemin katta yer almaktadır ${ }^{30}$. Tokat'ta 1875 yılına tarihlendirilen Latifoğlu Konağı örneğinde de zemin ve üst kat olmak üzere iki katlı konakta, zemin katta taşlık, günlük işlerin yapıldığ 1 ve aynı zamanda mutfak şeklinde kullanılan aşevi-iş evi ile kare planlı bir hamam bulunmaktadır. Latifoğlu Konağı'ndaki hamamı, önünde yer alan ocaklı soyunma mekânı ile, iki birimden meydana gelmektedir. Zemini taş döşemeli hamam, alttan 1sıtılmaktadır ${ }^{31}$.

Aydın ilinde 1923-1950 yılları arasına tarihlenen konut örneklerinde, genellikle duvarlarla çevrili bir avlu içinde konumlanan yaşam birimi ve bu birime bitişik mutfak ve yıkanma mekânı kütlesi görülmektedir. Ayrıca hamam, mutfak gibi ıslak hacimlerin odaların bulunduğu yaşam birimine bir koridor ya da mekânla bağlandığ tespit edilmiştir. Yıkanma mekânının düzenlenmesinde, döşeme altında yer alan ısıtma

28 Şahabettin Öztürk ve Mithat Çoşkun, Geleneksel Harput\&Elazığ Evleri (Elazığ: Elazığ Belediyesi Kültür Yayınları, 2014), 250.; Yüksel Sayan ve Şahabettin Öztürk, Bitlis Evleri (Ankara: Kültür Bakanlığı Yayınları, 1987), 35; Ergün Şimşek, Bitlis Evleri Geleneksel Konut Mimarlı̆̆ının Dünü, Bugünü, Yarını (İstanbul: Betav Yayınları, 2020), 51-52.

29 Yüksel Sayan ve Şahabettin Öztürk, Bitlis Evleri, 29, 30, 58, 61, 65, 74, 76.

30 Durduşen Öztürk, "Seydişehir Geleneksel Konut Mimarisi," (Yüksek Lisans tezi, Selçuk Üniversitesi, 2011), 190.

31 Mutlu Özgen, “Tokat Latifoğlu Konağı,” Vakiflar Dergisi 30 (2007), 487. 
sisteminden bahsedilmekle birlikte, zaman içinde mutfak ile birlikte konutun içine girdiği örnekler üzerinde durulmakta ancak detaylı restorasyon çalışması yapılmadığından bu konu netlik kazanmamaktadır ${ }^{32}$. Aydın'da, Söke ilçesindeki 1910-1911 tarihli Göktepe Evi örneğinde, bodrum katın kuzeyindeki odanın hamam şeklinde kullanıldığı kaynaklarda ifade edilmekte ancak tesisat ve ısıtma sistemine dair bilgiler bulunmamaktadır ${ }^{33}$.

\section{Manol Evi}

Aydın ili, Söke ilçesi, Kemalpaşa Mahallesi, Alay Sokak, No: 26 adresinde; 333 Ada, 11 Parselinde yer alan, kaynaklarda Bozdoğanlı Manol'un evi olarak geçen yapının mülkiyeti sonradan el değiştirmiştir. Yapan, yaptıran ve inşa tarihi bilinmeyen yapı uzun bir restorasyon süreci geçirmiştir ${ }^{34}$ (G. 1, G. 2). 20. yüzyıl ortalarına ait olabileceği düşünülen Manol Evi, bodrum kat üzerinde iki kattan ibaret ana bina, yapıdan bağımsız olarak planlanan iki katlı müştemilat ve yapıya bitişik ek binadan oluşmaktadır. Ana bina ve ek bina alaturka kiremit ile örtülüdür.

Konutun bodrum katında iki birim yer almaktadır. Depo olarak kullanılan bu birimlere hem yol cephesinden hem de avludan giriş sağlanmaktadır. Zemin kat ve birinci kat farklı düzendedir. Alt katta yan sofa ve yan sofaya bağlanan üç oda kullanılmışken, üst katta orta sofa ve beş oda görülmektedir. Konutun güneybatısında, konuta bitişik ek yapı, mutfak ve mutfağa bitişik hamam odasını bulundurmakta olup tek katlıdır.

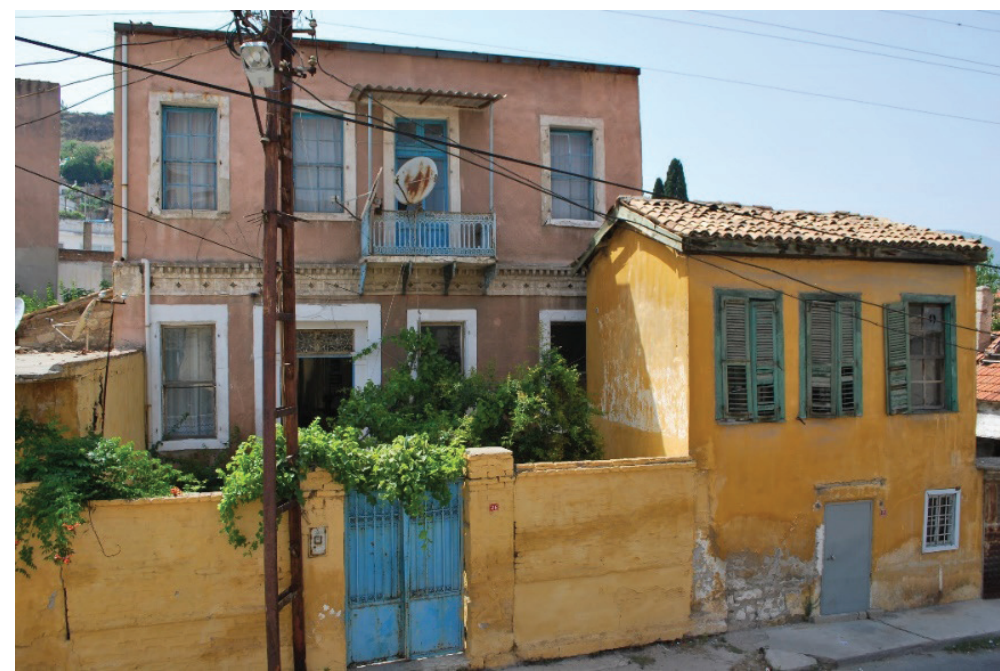

G. 1: Manol Evi, Alay Sokağa bakan cephe. Restorasyon öncesi. (Söke Belediyesi Arşivi, 2010)

32 Şimşek, “Aydın'da Mimarlık Mirası Olarak Cumhuriyet Dönemi Konutları," 48-49.

33 Alper Atıc1, "Söke'de Türk Mimarisi," (Yüksek Lisans tezi, Pamukkale Üniversitesi, 2018), 161.

34 Seçil Göven, "Söke'deki 19. Yüzyıldan Kalan Gayrimüslim Konutlarının Plan Tipleri Açısından Değerlendirilmesi; Kemalpaşa Örneği,” (Yüksek Lisans tezi, Süleyman Demirel Üniversitesi, 2019), 98. 


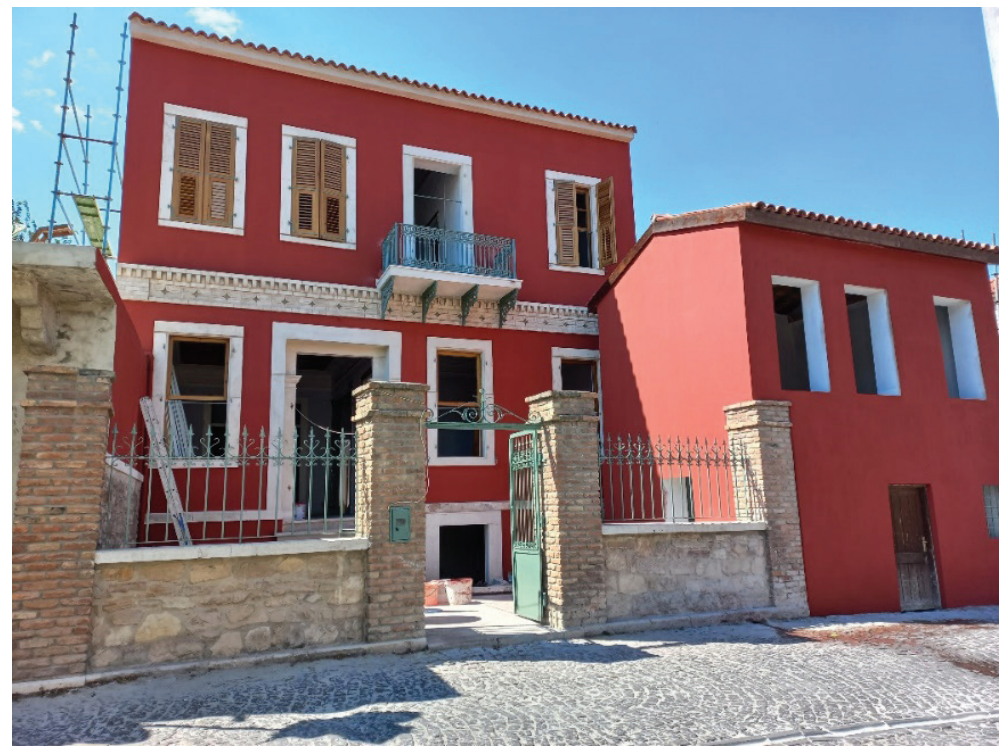

G. 2: Manol Evi Alay Sokağa bakan cephe. Restorasyon süreci (Söke Belediyesi Arşivi, 2021)

Üst katta iç sofalı, alt katta yan sofalı plan şemasının görüldüğ̈̈ Manol Evi’nin ön ve arka avlusu bulunmaktadır. Üst kata çıkılan merdiven, yapı boyunca uzanan sofaya çıkmaktadır. Üst kattaki beş oda sofaya açılmaktadır. Sofanın yola bakan cephesinde, girişin üzerinde madeni konsollarla taşınan balkon bulunmaktadır. Yapının bodrum katının tamamında taş malzeme kullanılırken diğer iki kat taş, ahşap ve kerpiç dolgulu kâgir tekniğinde inşa edilmiştir ${ }^{35}$.

Konut ile güneybatısında yer alan ek bina arasındaki geçiş, konutun zemin katındaki koridorla sağlanmaktadır. Geçiş bölümünde konutun koridorundaki gibi karosiman ${ }^{36}$ zemin kaplamas1 devam etmektedir (G. 3).

35 Göven, "Söke'deki 19. Yüzyıldan Kalan Gayrimüslim Konutlarının Plan Tipleri Açısından Değerlendirilmesi; Kemalpaşa Örneği," 106.

36 İstanbul, İzmir, Mersin gibi liman kentlerinde yaşayan Levanten aileler vasıtası ile Osmanlı coğrafyasında kullanım alanı bulan karosima, döşendikleri mekânları nemden koruyan ve çabuk temizlenebilen bir döşeme malzemesidir. Özellikle İzmir konutlarında cephelerin ve zeminlerin dekorasyonunda kullanılan karosiman, form, renk, motif, süsleme tasarımı ve kullanım yeri açısından çeşitlilik göstermektedir. Bk. Aygül Uçar, “İzmir Konutlarında Karosimanlar,” Sanat Tarihi Dergisi 23/1 (2014), 67-81. 


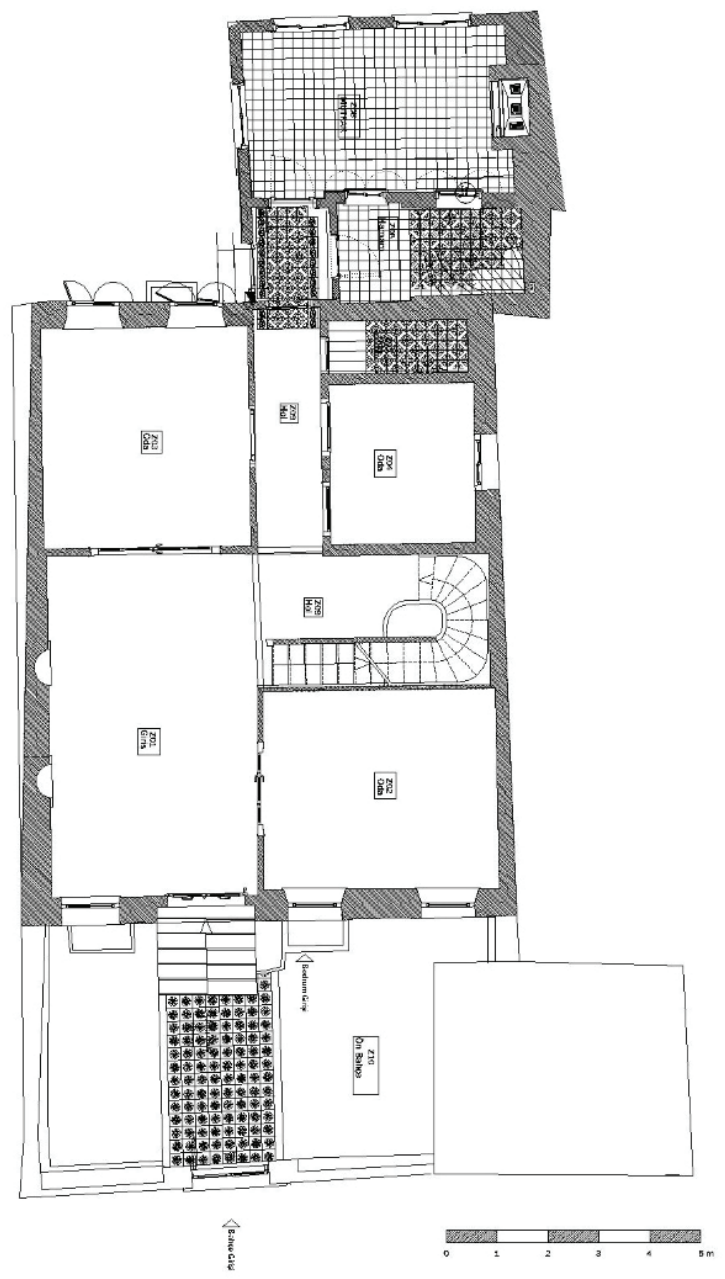

G. 3: Manol Evi zemin kat planı, 2020 (Mimar M. Şavkay tarafından çizilmiştir)

Manol Evi'nde, Söke Belediyesi tarafından 2010 yılında restorasyon çalışması başlatılmış ${ }^{37}$, evin Konuk Evi'ne dönüştürülmesi planlanmıştır. Restorasyon çalışmaları esnasında, tesisat ve 1sıtma sistemine dair fikirler sunan, tek birimden oluşan hamam odasına rastlanmıştır (G. 4). 

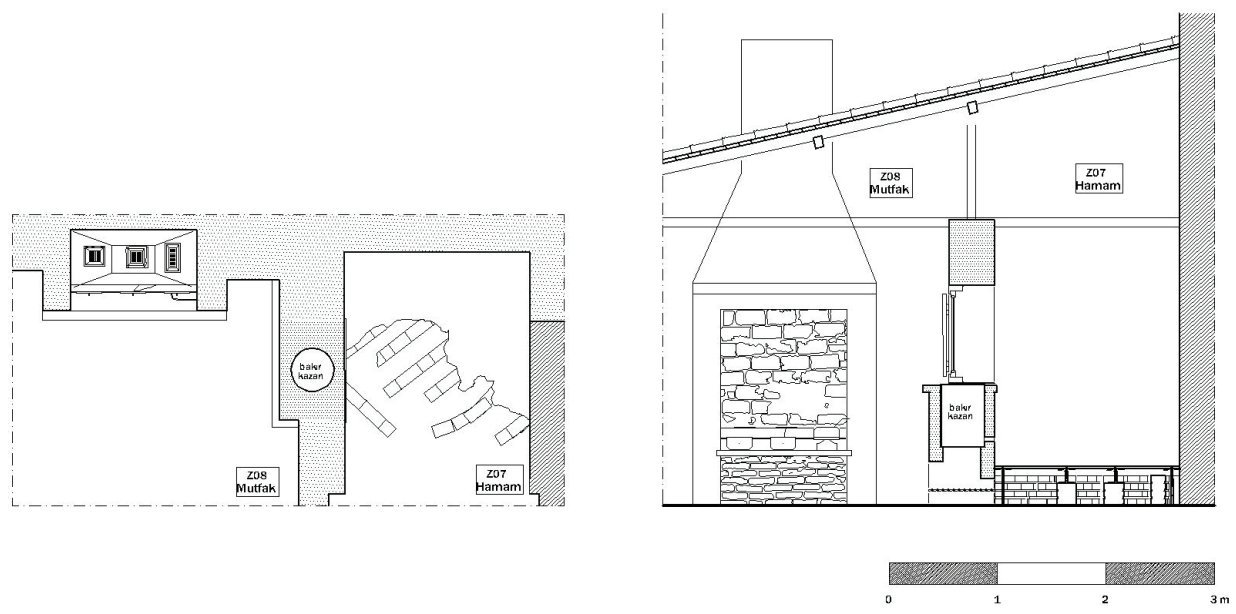

G. 4: Manol Evi mutfak ve hamam planı ve kesiti, 2020

(Mimar M. Şavkay tarafından çizilmiştir.)

Konuta ek olarak tasarlanmış üç mekândan oluşan ek yapı, mutfak, hamam ve hamamın önünde yer alan bir geçiş biriminden meydana gelmektedir. Mutfağa giriş, konutun zemin kat koridorundan, hamama giriş ise doğusundaki birimden geçilerek sağlanmaktadır. Ek binadaki mutfak biriminin tavanı, günümüzde çıtalı kontroplak kaplamalıdır. Duvarda bazı bölümlerde fayans, bazı bölümlerde sıva ve boya kullanılmıştır. Zeminde ise seramik kaplama yer almıştır. Bu birime, işlevine yönelik olarak ocak, ocağın iki yanında birer ocak nişi konulmuştur. Mutfak ile kuzeyindeki hamam odası arasında ahşap doğrama pencere kullanılmıştır. Mutfak birimi ile hamam arasındaki duvar, diğer duvarlara göre daha kalındır.

Çalışmanın esas konusunu teşkil eden hamam odasının tavanı günümüzde, mutfak ile benzer şekilde çıtalı kontroplak kaplamalıdır. Duvar ve zeminde ise seramik kaplama kullanılmıştır. Ancak, 2020 yılı içerisinde yapıda gerçekleştirilen restorasyon çalışmaları esnasında, zemindeki seramik kaplamanın altında geometrik motifli karosiman ortaya çıkarılmıştır (G. 5, G. 6). 


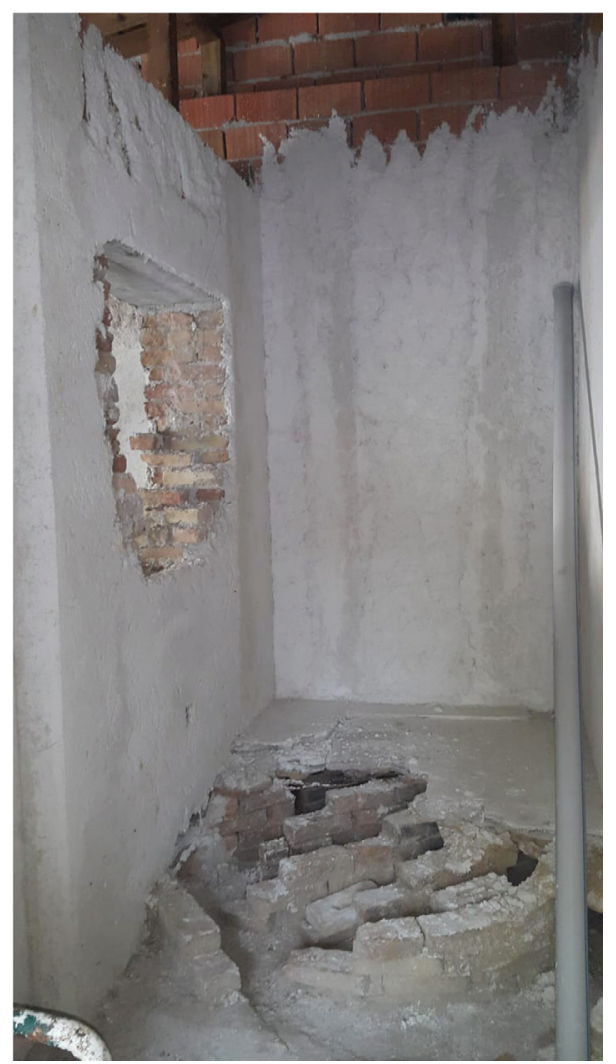

G. 5: Manol Evi hamamı (Söke Belediyesi Arşivi, 2020)

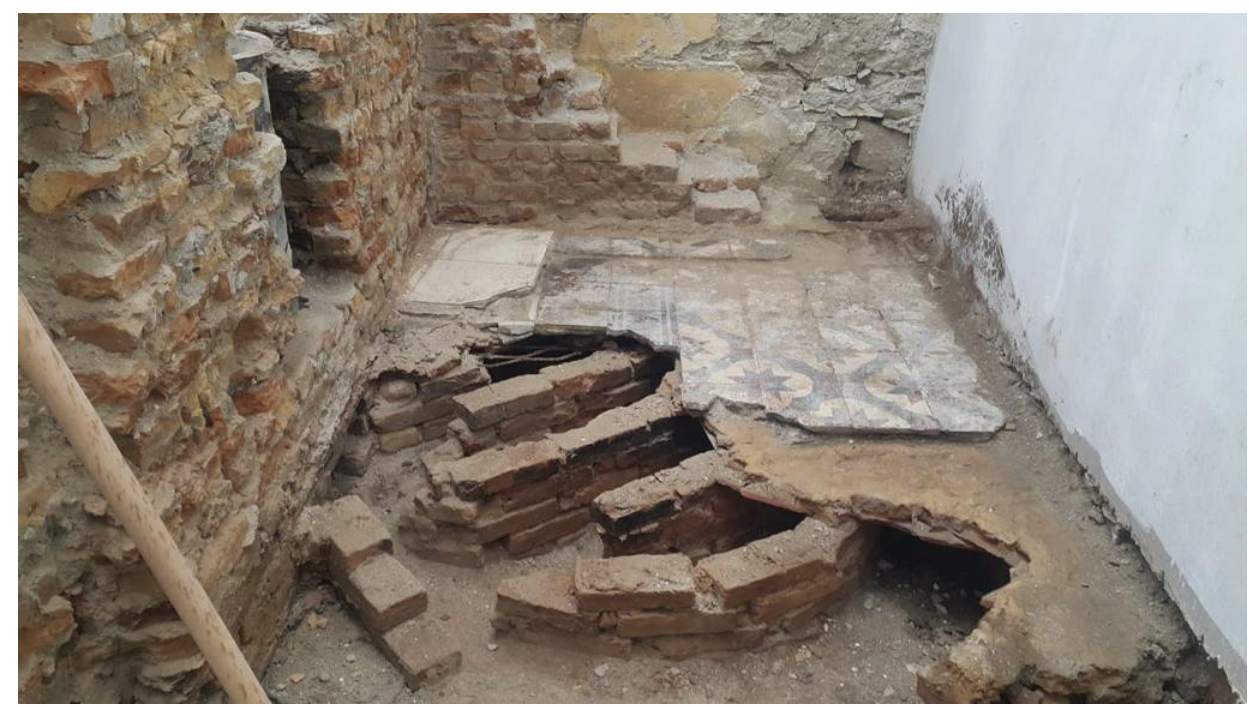

G. 6: Manol Evi hamamı zemin, ısıtma sistemi (Söke Belediyesi Arşivi, 2020) 
Restorasyon çalışması ile ayrıca, hamam odası 1sıtma sistemine ait 4 sıra tuğladan oluşan ayakları bulunmuştur. Hamamın güneyinde yer alan, mutfak birimi ile ortak kullanılan kalın duvar içerisinde de bakır kazan tespit edilmiştir (G. 7, G. 8, G. 9).

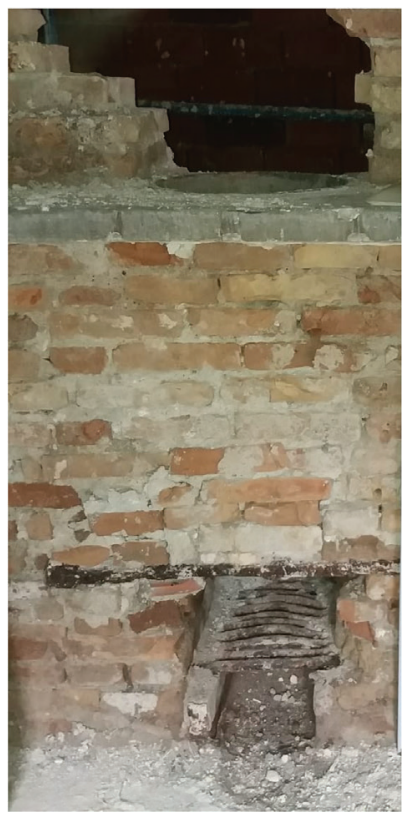

G. 7: Manol Evi hamamı, mutfak ile hamam arasındaki duvar (Söke Belediyesi Arşivi, 2020)

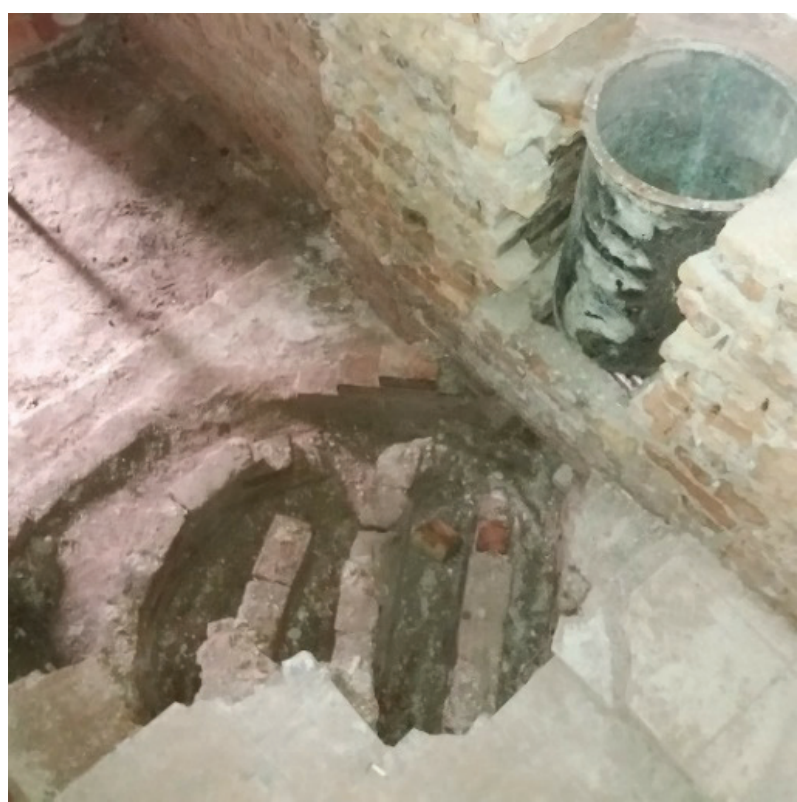

G. 8: Manol Evi hamamı, bakır kazan (Söke Belediyesi Arşivi, 2020) 


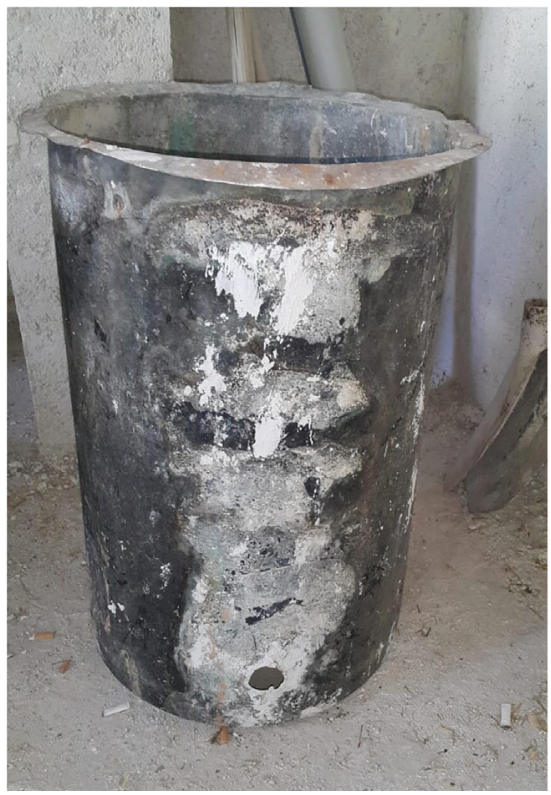

G. 9: Manol Evi hamamı, bakır kazan ve musluk bölümü (Söke Belediyesi Arşivi, 2020)

\section{Manol Evi Hamamında Tesisat ve Isıtma Sistemi}

2010 yılında Söke Belediyesi tarafından, Manol Evi’nde restorasyon çalışmaları başlatılmıştır. 2020 yılında restorasyon çalışması devam ederken, hamam odası tespit edilmiştir. Restorasyon çalışması günümüzde sürmekle birlikte, hamam odası tesisat ve 1sıtma sistemine dair bilgiler vermiştir.

Hamamlarda, tesisat ve 1sıtma sistemi incelendiğinde, hamama çeşitli kaynaklardan ulaştırılan suyun ve hamamın 1sıtılması, su deposunun altında ve hamamın taban döşemelerinden alt sevide bulunan külhanda yakılan ateş ile sağlanmaktadır. Su deposunda bulunan kazanın hemen altında ateş yakılmaktadır. Yanan ateşle birlikte ısınan kazan, depoda bulunan suyu da isıtmaktadır. Suyun hamamın çeşitli yerlerine ulaştırılması, duvarlar içindeki pişmiş topraktan yapılmış künklerle sağlanmaktadır ${ }^{38}$. Künklerle (pişmiş topraktan yapılmış su borusu) taşınan su, duvarlarda yer alan musluklar aracılığıyla kurnalara dökülmektedir ${ }^{39}$. Manol Evi hamamında, hamamlardaki bu kapsamlı tesisat sisteminin ev hamamında uygulandığı da görülmüştür. Hamamda ateş haznesi, madeni bir ızgara ile sınırlandırılmıştır ve bu bölümde kalın duvar içerisine yerleştirilmiş silindirik bakır kazanın alttan ısıtılması sağlanmıştır. Kazandaki sıcak suyun kullanımını sağlayan musluk, kazanın tabanına yakın bir bölümde, daire formunda bir delik hâlindedir. Isıtılmış su, muhtemelen musluk elemanının altında,

38 Yılmaz Önge, Anadolu'da XII-XIII. Yüzyıl Türk Hamamlarl (Ankara: Vakıflar Genel Müdürlüğü Yayınları, 1995), 45-52.; Canan Çakmak, Tire Hamamları (Ankara: Kültür ve Turizm Bakanlığı Yayınları, 2002$), 21$.

39 Çakmak, Tire Hamamları, 21. 
içerisinde soğuk suyun bulunduğu başka bir bölmeye aktarılarak banyoya hazır hale getirilmiştir. Banyoya hazır hâle gelen suyu muhafaza eden bir kurna ya da bir kazanın varlığ söz konusudur ancak kurnaya dair bilgi ya da iz bulunamamıştır. Yanan ateşten çıkan duman, bir baca vasıtasıyla tahliye edilmekte olup baca hamamın yola bakan kısa kenarı üzerinde, birimin batısında yer almıştır.

Hamamların tuvalet ve sıcaklık birimlerinde kullanılmış pis suyun atılması, zemin döşemesinde bulunan su kanalları ile sağlanmaktadır. Zeminde yer alan meyil ile sıcaklıktaki deliklere akıtılan pis su, zemin altındaki pis su boruları ile dışarı atılmak$\operatorname{tad}^{40}$. Ev hamamlarında da benzer bir düzen ile karşılaşılması zaruri olmakla birlikte, Manol Evi örneğinde pis su tahliyesine dair bir iz bulunmamaktadır.

Hamamlarda 1lıklık ve sıcaklık zemininin altında boşluk hâlindeki cehennemlik bulunmaktadır. Bu birimdeki boşluk, ayaklara oturan kemerlerle sağlanmaktadır. Külhandaki ateşten çıkan dumanlar, cehennemlik bölümünde dolaşarak hamamı zeminden 1sitmaktadır ${ }^{41}$. Roma hamamlarında da tabandan isitma sisteminin kökenleri tam olarak belirlenememekle birlikte MÖ 5. yüzyıldan itibaren döşeme altından yapılan 1sıtmanın çeşitli biçimleri belgelenmektedir ${ }^{42}$. Çalışmaya konu olan örnek ile birlikte, genel hamamlar ile tek birimden ibaret özel hamamlar arasında, 1sıtma sisteminin basitleştirilmiş bir kopyasının meydana getirildiği görülmüștür. Manol Evi hamamının döşemesi altında 4 sıra tuğladan oluşan bir cehennemlik meydana getirilmiştir. Hamamlardaki ayak ya da sütun düzeninin aksine, alanın büyüklügüne uygun şekilde, yanan ateşin 1sısının dağıtılması için alçak duvarlar kullanılmıştır. Bu bölümde 1sı kaybını engellemek adına, en dışta daire formunda bir sınır belirlenmiştir.

\section{Sonuç}

Bodrum kat ve üzerinde iki kattan oluşan Manol Evi, ana bina, ek bina ve yapıdan bağımsız müştemilattan ibarettir. Konutun güneybatısında, konuta bitişik ek binada mutfak ve mutfağa bitişik hamam odası yer almaktadır. 2020 yılında devam eden restorasyon çalışmasında ortaya çıkarılan hamam odası, tesisat ve 1sıtma sistemine dair fikirler sunmuştur.

Kaynaklarda kısıtlı sayıda bilgi edinilen, konut dâhilinde ya da müştemilat bölümünde yer alan hamam örnekleri incelendiğinde; hamam odası ile mutfak mekânı bağlantısı dikkat çekmektedir. Hamam bölümü zemin katta mutfak, kiler gibi birimlerle birlikte değerlendirilmiştir.

40 Yılmaz Önge, “Eski Türk Hamamlarında Su Tesisatı İle İlgili Bazı Detaylar.” I. Uluslararası Türk-İslam Bilim ve Teknoloji Tarihi Kongresi, 14-18 Eylül 1981 Bildiriler 5 (1981): 213-223.; Çakmak, Tire Hamamlarl, 22.

41 Kemal Ahmet Aru, Türk Hamamları Etüdü (İstanbul: İstanbul Teknik Üniversitesi Mimarlık Fakültesi Yayını, 1949), 37-40; Çakmak, Tire Hamamları, 22.

42 Yegül, Antik Çăg 'da Hamamlar, 88. 
Konutlarda yer alan hamam odas1 ile ilgili bilgiler yetersizdir. Konut dahilinde hamamı bulunan örnekleri konu alan çalışmalarda ise, tesisat ve 1sıtma sistemine dair yüzeysel bilgiler yer almaktadır. Manol Evi örneğinde, restorasyon aşamasında döşemenin kaldırılması ile, tesisat ve 1sıtma sistemine dair önemli verilerin ortaya çıkması, bu konuda yapılacak çalışmalara da örnek teşkil etmektedir.

Manol Evi hamamında, Roma ve Türk hamam mimarisindeki cehennemlik bölümünün küçük bir alan dâhilinde yansıtıldığg gözlenmiştir. Türk hamamındaki külhan bölümü ve su deposu içerisindeki suyun 1sıtılma prensibinin oldukça küçültülerek tekrarlandığı ev hamamı düzenlemelerinin Aydın'daki diğer konutlarda da görülmesi muhtemeldir. Ancak bu sonuca varabilmek için Aydın ilindeki geleneksel konutların yıkanma mekânlarına ait detaylı çalışmaların bulunması gerekmektedir.

Manol Evi hamamı örneğinde, ateş haznesi ve kazan, sıcak suyun akmasını sağlayan musluk, baca, 1sıtma sisteminin taşıyıcıları ortaya çıkmasına rağmen, hamam mekânında bulunması beklenen seki, kurna, lambalık gibi bölümlere dair bir iz ile karşılaşılmamıştır. Bu izlerin sonradan yapılan müdahalelerde ortadan kalkması muhtemel görülmüştür. Ancak Anadolu'daki kısıtll örnekler incelendiğinde seki ve lambalık ögelerinin kazanın bulunduğu, mutfak mekânı ile bağlantılı cephede yer aldığı görüşü ortaya çıkmıştır.

İncelenen ev hamamı örneği, 19. ve 20. yüzyıl konutlarındaki hamam odası uygulamalarına 1şık tutmakla birlikte, çarşı hamamlarının küçültülmüş birer örneğini de sergilemektedir. Tesisat ile ilgili hâlen bilinmeyenler bulunmasına rağmen, 1sıtma sisteminde cehennemlik düzeninin küçültülerek tekrarının bu bölümün ortaya çıkartılmış olması önemli görülmektedir.

Hakem Değerlendirmesi: Dış bağımsız.

Teşekkür: Görsel malzemenin ve planları sağlayan Söke Belediyesi’ne ve Mimar Mine Şavkay’a teşekkürlerimi sunarım.

Çıkar Çatışması: Yazar çıkar çatışması bildirmemiștir.

Finansal Destek: Yazar bu çalışma için finansal destek almadığını beyan etmiştir.

Peer-review: Externally peer-reviewed.

Acknowledgement: I would like to thank Söke Municipality and Architect Mine Şavkay for providing visual material and plans. Conflict of Interest: The author has no conflict of interest to declare.

Grant Support: The author declared that this study has received no financial support. 


\section{Kaynakça/References}

Arslan, Mehmet Erman. "Türkiye'deki Geleneksel Konut Tipolojisi ve Bileşenlerinin Sürekliliği.” Yüksek Lisans tezi, Beykent Üniversitesi, 2012.

Aru, Kemal Ahmet. Türk Hamamları Etüdü. İstanbul: İstanbul Teknik Üniversitesi Mimarlık Fakültesi Yayını, 1949.

Atıc1, Alper. “Söke'de Türk Mimarisi.” Yüksek Lisans tezi, Pamukkale Üniversitesi, 2018.

Bayazıt, Nigan. "Safranbolu Evlerinin Plan Tipolojisi ve Kullanıcı İhtiyaçları Hiyerarşisi.” TasarımKuram 17 (2014): 1-15.

Bektaş, Cengiz. Türk Evi. İstanbul: Yapı Kredi Yayınları, 1996.

Bozok, Emrah. “Türkçenin Söz Varlığında Temizlik Kavramı Alanı.” Doktora tezi, Ondokuz Mayıs Üniversitesi, 2018.

Çakmak, Canan. Tire Hamamları. Ankara: Kültür ve Turizm Bakanlığı Yayınları, 2002.

Dağ, Özgenaz. "Geleneksel Amasra Evleri Plan Tipolojisi.” Yüksek Lisans tezi, İstanbul Aydın Üniversitesi, 2017.

Davulcu, Mahmut. "Ormana Yöresi Geleneksel Konut Mimarisi ve Yapıcılık Geleneği.” Kalemişi 3/5 (2015): 47-96.

Deniz, Bekir. "Manisa Yöresi Köy Mimarisi.” Arkeoloji-Sanat Tarihi Dergisi 5 (1992): 17-46.

Eldem, Sedad Hakk1. Türk Evi Plan Tipleri. İstanbul: İstanbul Teknik Üniversitesi Mimarlık Fakültesi Yayını, 1995.

Ertem, Aylin. “Aydın Kent Merkezinin Tarihi Dokusunun İncelenmesi.” Yüksek Lisans tezi, Dokuz Eylül Üniversitesi, 2000.

Eyice, Semavi. “İznik'de Büyük Hamam ve Osmanlı Hamamları Hakkında Bir Deneme.” İstanbul Üniversitesi Edebiyat Fakültesi Tarih Dergisi 11/15 (1960): 99-120.

Eyice, Semavi. "Hamam I. Tarih ve Mimari." TDV İslam Ansiklopedisi. C. 15. İstanbul: Türkiye Diyanet Vakfi Yayınları, 1997, 402-430.

Göğebakan, Yüksel. "Karakteristik Bir Değer Olan Geleneksel Türk Evi’nin Oluşumunu Belirleyen Unsurlar ve Bu Evlerin Genel Özellikleri.” İn̈nü Üniversitesi Kültür ve Sanat Dergisi 1/1 (2015): 41-55.

Göven, Seçil. "Söke’deki 19. Yüzyıldan Kalan Gayrimüslim Konutlarının Plan Tipleri Açısından Değerlendirilmesi; Kemalpaşa Örneği.” Yüksek Lisans tezi, Süleyman Demirel Üniversitesi, 2019.

Günay, Reha. Türk Evi Geleneği ve Safranbolu Evleri. İstanbul: YEM Yayınları, 1998.

Oymanel, Sabit, Hatice Kıran Çakır ve Özlem Sallı Bideci. "Geleneksel Mimari Uygulamaların Yorumlanmas1.” 6th International Advanced Technologies Symposium, 16-18 May 2011 (Elazığ: Elazığ Üniversitesi Yayınları, 2011), 75-80.

Önal, Raziye Çiğdem. "Erzurum/İspir İlçesinde Geleneksel Ev Mimarisi.” XX. Uluslararası Ortaçă̆ Türk Dönemi Kazıları ve Sanat Tarihi Araştırmaları Sempozyumu, 02-05 Kasım 2016 Bildiriler 2 (Sakarya: Sakarya Üniversitesi Yayınları, 2016): 743-760.

Önge, Yılmaz. "Eski Türk Hamamlarında Su Tesisatı İle İlgili Bazı Detaylar.” I. Uluslararası Türkİslam Bilim ve Teknoloji Tarihi Kongresi, 14-18 Eylül 1981 Bildiriler 5 (1981): 213-223.

Önge, Y1lmaz. “Anadolu'da Türk Hamamları Hakkında Genel Bilgiler ve Mimar Sinan’ın İnşa Ettiği Hamamlar.” Mimarbaşı Koca Sinan Yaşadı̆̆ Çă̆ ve Eserleri 1 (İstanbul: Vakıflar Genel Müdürlüğü Yayınları, 1988). 
Önge, Yılmaz. Anadolu'da XII-XIII. Yüzyıl Türk Hamamları. Ankara: Vakıflar Genel Müdürlüğü Yayınları, 1995.

Özgen, Mutlu. “Tokat Latifoğlu Konağı.” Vakıflar Dergisi 30 (2007): 485-502.

Öztürk, Durduşen. "Seydişehir Geleneksel Konut Mimarisi." Yüksek Lisans tezi, Selçuk Üniversitesi, 2011.

Öztürk, Şahabettin ve Çoşkun, Mithat. Geleneksel Harput\&Elazı̆̆ Evleri. Elazı̆̆: Elazığ Belediyesi Kültür Yayınları, 2014.

Sayan, Yüksel. Uşak Evleri. Ankara: Kültür Bakanlığı Yayınları, 1987.

Sayan, Yüksel ve Şahabettin Öztürk. Bitlis Evleri. Ankara: Kültür Bakanlığı Yayınları, 2001.

Sezgin, Haluk. "Yöresel Konut Mimarisi ve Türkiye'deki Örnekleri Hakkında.” Tasarım Kuram Dergisi 3/4 (2006): 1-20.

Şimşek, Ergün. Bitlis Evleri Geleneksel Konut Mimarlığının Dünü, Bugünü, Yarını. İstanbul: Betav Yayınlar1, 2020.

Şimşek, Gökçe. “Aydın’da Mimarlık Mirası Olarak Cumhuriyet Dönemi Konutları.” Megaron 10/1 (2015): 43-56.

Tuluk, Ömer İskender. “Erken 20. Yüzyıl Çorum Evlerinde Banyo Teknolojisi.” Orta Doğu Teknik Üniversitesi Mimarlık Fakültesi Dergisi 27/2 (2010): 61-82.

Uçar, Aygül. “İzmir Konutlarında Karosimanlar.” Sanat Tarihi Dergisi 23/1 (2014): 67-81.

Uşma, Gökhan ve Urfalığlu, Nur. "Geleneksel Van Evlerinin Cephe Özellikleri ve Tipolojisi Üzerine Bir İnceleme.” Çukurova Üniversitesi Mühendislik Mimarlık Fakültesi Dergisi 33/1 (2018): 1-16.

Yaşaroğlu, Mehmet Kâmil. "Hamam III. Fıkıh.” TDV İslam Ansiklopedisi. C. 15. İstanbul: Türkiye Diyanet Vakfı Yayınları, 1997, 433-434.

Yegül, Fikret. Antik Çă̆’da Hamamlar ve Yıkanma. İstanbul: Homer Kitabevi, 2006. 